\title{
Concession implies causality, though in some other space
}

\author{
Arie Verhagen
}

This paper addresses the issue of the relationship between concessivity and causality, in the sense that these concepts can and should be construed as parallel, concessivity being in some sense a negative counterpart of causality. It is argued that in order to avoid the risk of internal contradiction and other conceptual problems, it is necessary to construe the relationship in terms of partly but not completely similar 'points of view', or mental spaces. While aiming for an explanation of obvious facts of interpretation and usage, the discussion focuses on clarification of conceptual questions.

\section{Introduction}

It is well known, as noted by König and Siemund (this volume), that causal and concessive relations and the linguistic means for marking them are conceptually related in interesting ways. Theoretical analyses of these relations should therefore provide explanations for this connection. The kind of phenomena König and Siemund draw attention to involve, inter alia, a parallelism in the possible interpretations of sentences such as the following:

(1) The house is no less comfortable because it dispenses with airconditioning.

(2) The house is no less comfortable, although it dispenses with airconditioning.

Especially if realized with a particular intonation contour, (1) can be read as a paraphrase of (2): with the negation taking wide scope, including the causal clause, (1) can express the same relationship as (2) with the negation taking narrow scope, excluding the concessive clause. Roughly: denying "the house is less comfortable because it dispenses with air-conditioning" can be equivalent to stating "it is no less 
comfortable" while conceding "it dispenses with arr-conditioning" Even if one doubts the equivalence of (1) and (2) in all circumstances, the fact that for certain purposes or in certain respects they can be taken as parallels suffices to establish an interesting connection between concessivity, causality, and negation, one which poses a criterion of adequacy for theories of concessivity

Konig (1991) explores the idea that this connection might be captured in a very direct way, viz by considering it an instance of duality As already pointed out at the end of that paper, there appear to be some fundamental problems for this approach as soon as one goes beyond the very first examples that inspired it (cf also section 3 of Konig and Siemund (this volume)) One of the problems is the asymmetry in the relationship Negation of causality may lead to an interpretation as concessive, but (wide scope) negation of concessivity does not allow for an interpretation as causality It is not the case that John falled his exams although he worked hard cannot be interpreted as "John passed his exams because he worked hard"-if it is interpretable at all Another issue is that in this way the relationship can at best be stipulated, not explained It is evident that only a wide scope interpretation of a negation of causality can correspond to a concessive reading, but why should this constraint hold in precisely this way? All in all, it seems unavoidable to conclude that concession cannot be taken as negated causality in any simple sense However, this should not lead to the conclusion that the original observation was misguided-the parallel between causality and concessivity still requires an explanation

In fact, there is yet another set of interesting connections between causality and concessivity (or more generally contrast), viz the fact that they can be applied in parallel ways in different conceptual domains in the sense of Sweetser (1990) Interestingly, it is also true that this theory at some point runs into the same problem that the parallel is not complete, and that it is not obvious whether the difference can be accounted for in a principled manner It is this connection that I will use as a starting point for an alternative analysis of the relationship between causality and concessivity

\section{Causals and concessives in two domains}

One of the main motives for Sweetser's domain distinction is that it provides a mechanism for accountıng for the fact that similar types of 
polysemy show up in different expressions Consider the ambiguity of modal verbs in terms of deontic vs epistemic interpretations He must come home is an example of deontic usage, it describes some obligation in the world ( $\mathrm{viz}$ in the person referred to) He must be home (by now) illustrates epistemic usage, it locates an obligation (viz to conclude "He is home" on the basis of the avallable evidence) in the conceptualizer rather than in the world being conceptualized It is no coincidence that this type of polysemy resembles the difference between distinct types of usage of the English conjunction because, as exemplified in the contrast between (3) and (4)

\section{(3) John passed his exams because he worked hard}

\section{(4) John worked hard, because he passed his exams}

In (3), the causal relation holds between the facts that John passed his exams and that he worked hard (1 e in the "content domain") In (4), on the other hand, it holds in the conceptualizer's mind, $1 \mathrm{e}$ the proposition that John worked hard is epistemically caused by an argument based on the knowledge that he passed his exams Postulating a systematic conceptual distinction between content and epistemic domains for the application of the meaning of modal verbs as well as connectives provides a unified account for such phenomena, and thus has great explanatory power

At first sight, Sweetser's approach is further corroborated by the fact that it also applies to connectives with some negative aspect of meaning, 1 e concessives However, precisely this application also produces a conceptual dilemma, as we shall see

On the one hand, cases like (5) and (6) seem to be clear negative parallels to (3) and (4)

\section{John did not pass his exams although he worked hard}

\section{John did not work hard, although he passed his exams}

Intuitively, one could say that in (5) the real-world causal connection between passing exams and working hard is in some sense negated, so that this would be a case of concession in the content domain Analogously, what is negated in (6) seems to be the validity (in this case) of the inference from the knowledge of John's passing his exams 
to the conclusion of his working hard, so that this would be a case of concession in the epistemic domain (cf the examples and paraphrases of 'adversatıve' conjunctions in Sweetser 1990 79) Thus what we have here is another interesting connection between causality and concessivity if the latter is the negative counterpart of the former, then, given the theory of domains, we should expect it to be applicable in a parallel fashion in the distinct domains, and this is precisely what appears to be the case

On the other hand, Sweetser explicitly draws attention to the fact that for the adversative conjunction but (arguably even more general and semantically simpler than concessive although), it is hard to find clear examples of content usages The point is that a contrastive relation always allows for a construal as a relation of reasoning, involving relations between arguments and conclusions, and is never clearly restricted to real-world relations Consider the following parallel to the concessive examples above

\section{(7) John worked hard, but he did not pass his exams}

The contrast signalled by but cannot be sufficiently explained in terms of the real world facts of working hard and not passing, after all, these situations are not at all incompatible in the real world, as is clear from the fact that they co-occur quite regularly In order to explain the contrast it seems necessary to invoke, among other things, some reasoning process on the basis of general and specific knowledge licensing the expectation that John could pass his exams, so that the contrast can be construed as holding between this expectation and the actual fact of John's falling

In a way, such a move even seems natural in some general sense, as it is actually not really clear what the content of the concept of 'contrast' should be if we were to try to locate it completely in the world, $1 \mathrm{e}$ without reference to some person perceiving or conceptualizing a contrast (Sweetser 1990 103-104) However, such a move does create a dilemma If we call the use of but inherently epistemic (acknowledging that the concept 'contrast' requires reference to reasoning), then we would seem obliged to call although inherently epistemic as well, because this also involves contrast (5) is as contrastive as (7), and it does in fact seem to require reference to the same kind of (unfulfilled) expectations But calling all uses of although epistemic would deprive us of a way to account for the difference between (5) and (6), as well as 
for the parallel between this pair on the one hand, and (3) and (4) on the other.

My purpose in the remainder of this paper is to argue that the effects previously analyzed in terms of domains can and should be derived from the construction of mental spaces, with (especially) negative semantic elements taken as instructions for setting up alternative mental spaces, and that precisely this reconstruction avoids the dilemma just noted. More exactly, an approach using mental spaces, as dynamically constructed domains for the interpretation of linguistic elements, allows us to simultaneously (a) account for the parallel between (3)/(4) and $(5) /(6)$, (b) claim that contrastive-as opposed to causal-relations necessarily involve reference to some reasoning process, and (c) account for the connection between concessivity and (negated) causality.

\section{Elements of a solution}

Let me begin by illustrating the idea with the relatively simple example (5), repeated here for convenience:

\section{(5) John did not pass his exams although he worked hard.}

As is well established in the literature on concessives, the specific nature of such a relation crucially involves the fact, as König (1991) described it, that two propositions are asserted "against the background of an assumption." Analyses explicating this idea in terms of logical operators have been undertaken by Pasch (1992a, 1992b, 1994:16-27) and König (1991, 1994), among others. There are differences among these analyses, but the general idea is as follows:

(8) "p although q" means:
a. Truth conditions: $p \& q$
b. Presupposition: $q \rightarrow \neg p$

Taken at face value this leads to an internal contradiction (implying both $\mathrm{p}$ and $\neg \mathrm{p}$, or both $\mathrm{q}$ and $\neg \mathrm{q}$ ), and is thus minimally in need of additional mechanisms or assumptions. Pasch, acknowledging this, seems to assume that a speaker of anything of the form (8) actually utters something that is necessarily false. Others are clearly more hesitant to 
draw such a conclusion. In any case, what seems to be needed is to be more clear about what exactly is meant by the idea of "background assumption", "discourse presupposition", or whatever it is called (cf. König 1991). It is precisely at this crucial point that Mental Space theory (Fauconnier 1994, 1998; Fauconnier \& Sweetser (eds.) 1996) can offer clarification, in a very natural way. Put informally, the way we interpret (5) is that the speaker, working with some general rule licensing certain inferences (in this case for example "Normally, working hard increases your chances of passing" or "The harder you work, the likelier it is that you will pass your exams", and their corollaries), reports her knowledge of a particular situation that may be judged to satisfy the criteria for application of the rule, but nevertheless does not conform to it. In Mental Space terms: the speaker makes us set up a 'point of view' in which a general rule, or "topos" (cf. note 1), holds of the form $\{\mathrm{P} \rightarrow \mathrm{Q}\}$ (the capital letters indicate that the propositions involved are generalizations, not particulars). Furthermore, in this mental space not only the general topos holds, but also some particular proposition $\mathrm{p}$, which counts as an instance of $\mathrm{P}$. Consequently, within this mental space, the topos combined with $p$ licenses a causal inference, viz. of another particular proposition $q^{2}$ Represented graphically:

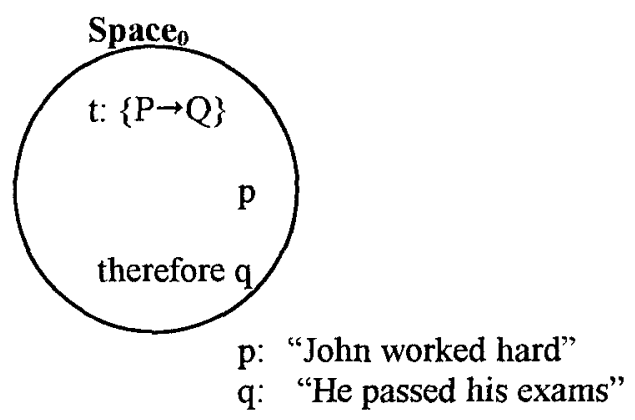

Figure 1. Single Mental Space configuration

However, understanding the concessivity of John did not pass his exams although he worked hard involves understanding that such a mental space is to be set up as a second space projected from the speaker's actual mental space. By uttering although $p$ the speaker instructs the hearer to set up two similar but distinct mental spaces in which $\mathrm{p}$ is true; in one (Space ${ }_{1}$, with the same structure as in Figure 1, but now projected from the speaker's own mental space) the causal inference " $p$ therefore 
q" is valid, while in the speaker's mental space (Space), the truth of q is denied so that this causal inference is not valid. Represented graphically:

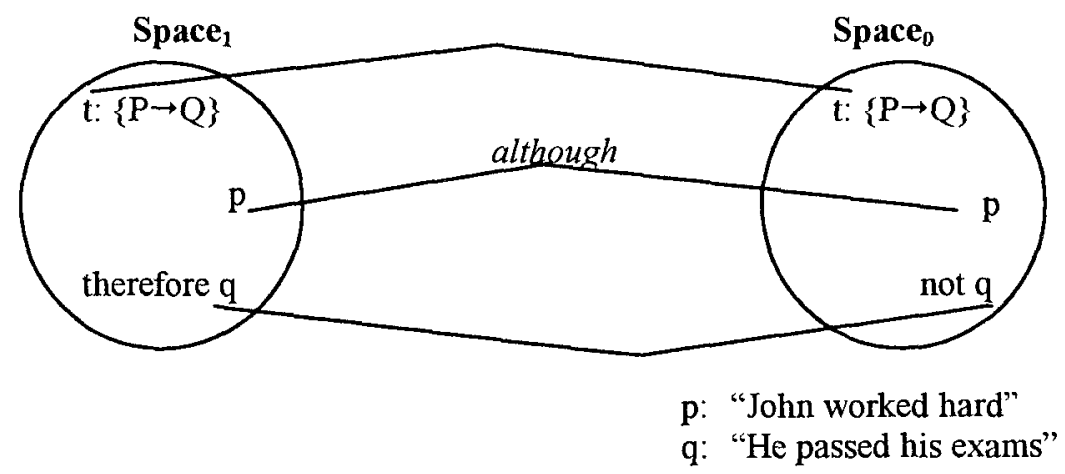

Figure 2. Elementary Mental Space configuration for concessivity

This analysis provides an immediate account, in a natural way, for the often noted close relationship between concessivity and causality without the problems involved in 'mixing' them in one system of representation. It seems to capture a crucial feature of the concept of concession: someone acknowledges that in highly similar circumstances a mind very similar to one's own draws a valid causal inference, while this inference is actually not valid.

The representation in Figure 2 uses the standard apparatus of Mental Space theory, especially connectors across spaces (the lines connecting elements in one space to another). It includes the idea that information may get mapped from one space to another without explicit specific instruction (cf. Fauconnier 1998). In particular, the topos $\{\mathrm{P} \rightarrow \mathrm{Q}\}$ may transfer from Space ${ }_{1}$ (in which it is necessary as licensor of the causal inference) to Space $_{0}$ 'for free': one would normally interpret the speaker as still adhering to the idea that hard work ordinarily increases the chances of passing (considering this particular case an exception to the rule). But strictly speaking this interpretation is optional (hence the parentheses in Space $e_{0}$ in Figure 2); it may be cancelled, for instance, when the speaker goes on to construe her observation as an argument against the general assumption (as in: Although he worked hard, John failed the exam; so you see that you are wrong in suggesting that working hard leads to success). In such a case, she still evokes a mental space in which the topos and the related causal inference hold, but then 
the topos is explicitly excluded from the speaker's own space. In any case, the topos is neither necessarily entailed nor contradicted within Space $_{0}$, something that is very hard to capture without distinguishing between the two spaces.

\section{Excursion: mental spaces and multiple voices}

I just characterized concession as envisaging another mind, similar to one's own, drawing a causal inference that is valid in highly similar circumstances but not in actuality. This formulation suggests a parallel to another approach to the analysis of 'viewpoints' in a discourse, viz. Ducrot's theory of "polyphony" (Ducrot 1984, 1996). The concepts of mental spaces, as I have so far used the term, and Ducrot's concept of multiple 'voices' being present in the interpretation of a single utterance, may be seen as no more than different labels for what is essentially the same fundamental insight. To an important extent, I do in fact believe this to be true. However, there are some differences that one should be aware of.

First, the term "mental spaces" seems to put more emphasis on an individual's mental capacity for entertaining different viewpoints, whereas "multiple voices" more strongly evokes the inherent dialogic nature of verbal communication. At this point $I$ actually see no incompatibility; the individual's capacity can be seen as something that is put to use in actual linguistic communication (when the abstract mental spaces are assigned to the minds of actual people, as it were), as well as something that has emerged in the individual as a result of interaction with actual other persons during childhood. In other words, though much may still be unknown about the empirical issue of the precise relationship between individual and social cognition and the ways they develop, there does not seem to be an a priori conceptual opposition between mental spaces and polyphony.

Second, Ducrot distinguishes between three specific types of voices in an utterance, especially (1) physical producers of pieces of discourse, (2) 'locutors' (those who may be held responsible for the content of the utterance, and who do not necessarily coincide with the physical producers; I will designate these as 'conceptualizers' below), and (3) 'enunciators' (those whose viewpoints are represented in the discourse). I do not know of an explicit parallel to these distinctions in mental space terms. Something that is conceivably parallel to the distinction between 
the latter two notions will turn out to be relevant for the discussion below, but I think it is an immediate consequence of other features of the analysis and does not require independent stipulation.

Third, Ducrot's concept of polyphony is intimately linked to his theory of argumentativity in natural language. At this point I think there is both a real difference between the mental space and the polyphony approaches, ànd a point where Mental Space theory can profitably be augmented, if we take 'argumentation' not so much in the sense of verbal conflict, but more in the sense of 'trying to influence a person's point of view', 'orienting one's addressee(s) towards some conclusion'. I think this notion of argumentative 'orientation' (in my view more important for linguistic analysis than the notion of argumentation in itself) is very useful, and can help us to see how mental spaces work in certain areas (such as scalar semantics, or certain phenomena of language change). Still, for the purposes of the analysis of discourse as such, the mental space terminology seems to me to involve the minimum of necessary assumptions concerning the nature of discourse interpretation. Analysts will agree, I assume, that any approach to discourse interpretation has to take into account that people can manage multiple viewpoints simultaneously, whereas the question if these are 'better' viewed as individual psychological phenomena or as dialogic, social ones, requires more specific assumptions and evidence. This is the reason why I prefer to use the mental space terminology here. But let us return to the main theme now.

\section{Solving the paradox}

\subsection{Epistemic causality}

Setting up two related but distinct mental spaces in the construction of a concessive relationship is crucial in avoiding the attribution of contradictory beliefs to the conceptualizer of a concessive utterance, as seems unavoidable in an analysis that tries to analyze concessivity only in terms of manipulations of propositions (cf. the beginning of section 2). ${ }^{3}$ Another interesting feature of the mental space approach is that the same apparatus holds some promises for the analysis of (concessive) conditionals and counterfactuals (cf. If John had worked hard, he would have passed or Even if John had worked hard, he would not have passed) and thus for an account of the similarities (as well as the 
differences) between these kinds of relations and concessives. ${ }^{4}$ But in the present context it is especially relevant that the idea of levels of interpretation can be reconstructed, at least partly, in terms of mental spaces: whenever the interpretation of a discourse relation (or a connective) between two segments involves the construction of two similar mental spaces such that certain inferences are valid in one but not in the other, then this interpretation is necessarily epistemic. What makes an example like (5) look like a case of argumentation, hence of an epistemic relation, is the construction of more than one mental space in which different inferences are valid. But what makes it look like 'concessivity in the content domain' is the fact that the background causal inference in Space $_{1}$ relates to the world. The qualitative difference between causal and concessive relations is that the former do not necessarily lead to the construction of multiple spaces while the latter do. It is the case of a causal relation within a single mental space that provides the instances of pure 'content causality'. It is the parallel case with two mental spaces representing distinct epistemic stances towards the same causal relations that provides instances of apparent 'content concessivity'.

At the same time, the presence of two mental spaces makes even such content concessives into cases of epistemic relations, and thus parallel to epistemic causality. The point is that the actual use of an epistemic causal relation, by Gricean principles, also involves the construction of multiple spaces, in the following way. Recall that the epistemic interpretation of a causal relation or connective as in (4), repeated below, amounts to construing the second segment as an argument for the conclusion in the first:

(4) John worked hard, because he passed his exams.

Content causality, e.g. stating John passed his exams and then going on to say how this came about (...because he worked hard) allows for the first clause to be taken as representing established knowledge, and the second as the only news. But when the second segment is an argument as in (4), then its being uttered would be beside the point, violating the maxim of relevance, if the first clause was already taken to represent undisputed knowledge at its being uttered: one does not provide support for information that one knows will remain unchallenged. Consequently, if a speaker provides an argument in the second clause (i.e. produces a relation of epistemic causality), she projects a mental 
space with a non-positive epistemic stance (unlike her own) towards the proposition expressed in the first clause:

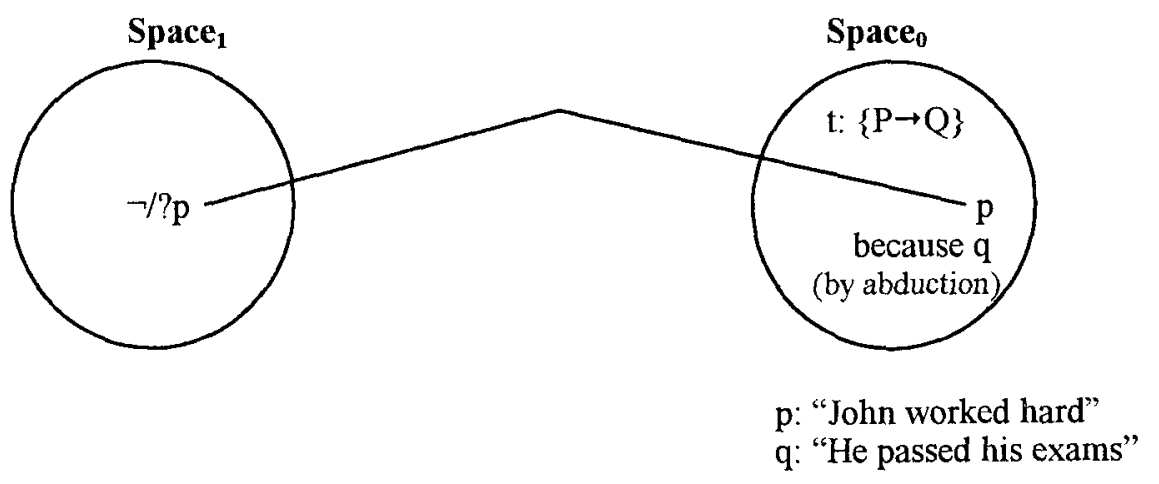

Figure 3. Elementary Mental Space configuration for epistemic causality ${ }^{5}$

By the same reasoning, the content reading of the causal relation in (3) does not involve the construction of another mental space representing another epistemic stance:

\section{(3) John passed his exams because he worked hard.}

As has been observed frequently, the content reading provides only one statement, e.g. an answer to a single question of the type "Why?" or "How?", and thus in a sense presupposes the proposition that John passed his exams; this is what I called the "undisputed information" interpretation of the first clause above. Thus in a content reading of $p$ because $q$ the speaker precisely does not project a mental space in which the validity of $p$ is not (completely) certain. ${ }^{6}$ We can now formulate what it is that makes epistemic causality parallel to contrast (including, in particular, concessivity): the construction of two mental spaces with distinct epistemic stances towards a proposition.

\subsection{Epistemic concessivity}

We have now provided an account, by using the mental space approach, of the parallel between 'simple' concessivity and both content causality (the inference in one mental space relates to real-world causality), and epistemic causality (the interpretation involves two mental spaces with 
distinct epistemic stances). The remaining question is how the apparent 'epistemic concessive' (6) fits in:

\section{John did not work hard, although he passed his exams.}

What appears to be going on here is recursive mental space building. An abductive causal reasoning process as in Figure 3 is embedded in the space representing the projected epistemic stance in Figure 2 (Space $)_{1}$. Since such a reasoning process itself involves two mental spaces, what results is the constellation of mental spaces depicted in Figure $4:^{7}$

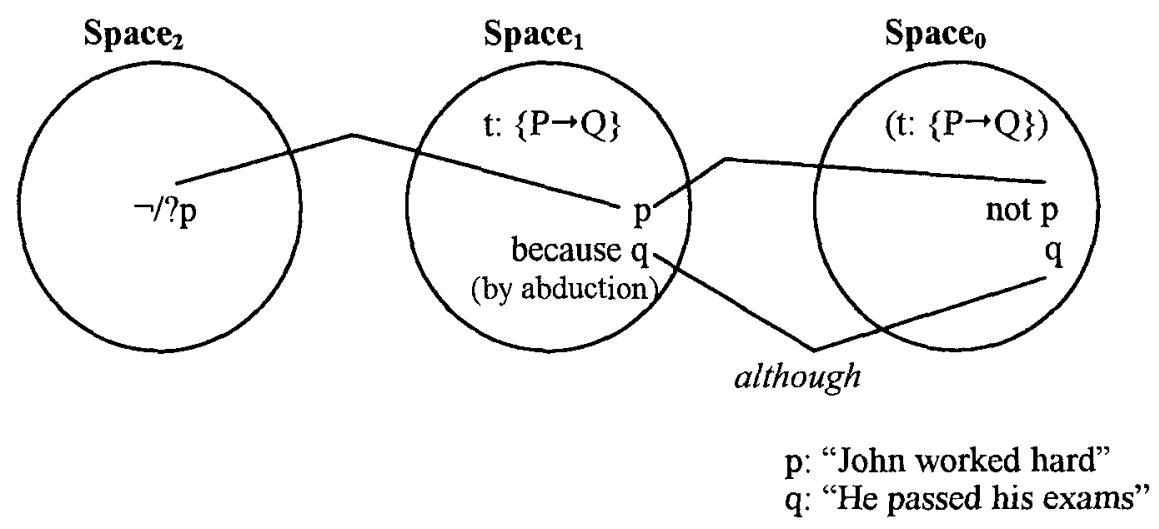

Figure 4. Mental Space configuration for 'epistemic concessivity'

That is, in uttering (6): John did not work hard ["not p" in Space 0 ], although he passed his exams [" $\mathrm{q}$ " in Space ${ }_{0}$ ], in particular through the use of although, the conceptualizer projects another mental space (Space $)_{1}$, containing the abductive inference that John must have been working hard [" $p$ " in Space $_{1}$ ] because he passed his exams ["q" in Space $\left._{1}\right]$, and then invalidates this inference by denying its conclusion. This analysis is corroborated by the fact that (6) allows for the following explication: "Actually, the inference that John must have been working hard considering that he passed his exams, is invalid: it is both true that he passed [=second clause], and that he did not work hard [=first clause]". The applicability of such a paraphrase is predicted on the basis of the present analysis: since the mental space projected immediately from the conceptualizer's space contains an instance of epistemic causality, this space projects yet another mental space as its background, given our analysis of epistemic causality in the previous section. 
The parallel between epistemic causality and epistemic concessivity is that both involve a mental space containing argumentation, which therefore projects yet another mental space; the difference is that in the latter case this constellation is the background of the conceptualizer's space rather than that space itself. The constellation of the two leftmost spaces in Figure 4 is identical to the one for epistemic causality depicted in Figure 3, the two rightmost spaces in Figure 4 correspond to the elementary constellation of concessivity in Figure 2 . The parallel between concessives in general and epistemic causality is that both kinds of relationships involve more than one space with a difference in epistemic stance towards a proposition.

It is the possibility of embedding spaces that allows us to simultaneously account for differences and commonalities between the pairs of sentences that we started out with. The mental space approach thus provides a way to account for multiple levels of interpretation without multiplying levels in the theory: the same mechanism of projecting a mental space from another one may sometimes be applied recursively.

\subsection{Concessivity and negated causality}

I now want to show how the mental space approach also provides an analysis of the connection between concessivity and negated causality, i.e. the (partial) overlap between the wide-scope interpretation of (1) and the narrow-scope interpretation of (2), repeated here for convenience:

(1) The house is no less comfortable because it dispenses with airconditioning.

(2) The house is no less comfortable, although it dispenses with airconditioning.

What the relevant interpretations have in common is that an alternative space is set up in which a causal inference "the house is less comfortable" (q) is licensed on the basis of a topos of the type "Airconditioning normally makes a house more comfortable", and that this inference is invalidated in the conceptualizer's space, while it is true in 
both spaces that "the house dispenses with air-conditioning". The mental space representation of this interpretation is given in Figure 5:

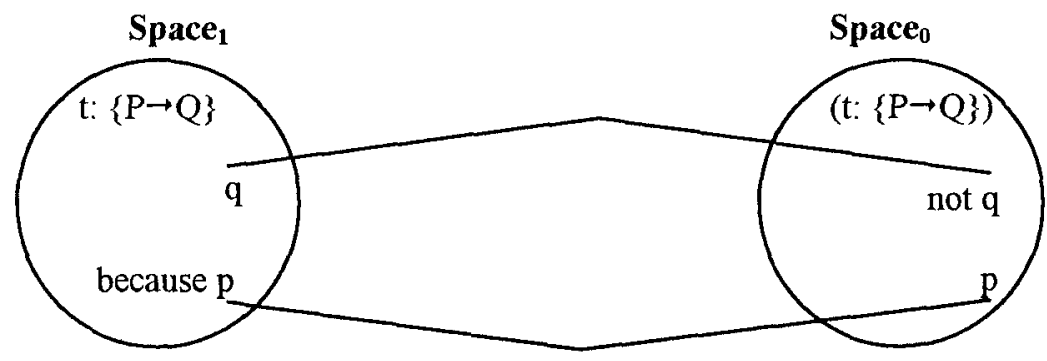

$\mathrm{p}$ : "The house dispenses with air-conditioning"

q: "It is less conformtable"

Figure 5. Mental Space representation of (1)/(2)

It is now evident that the concessive interpretation of (1) entails that the element because marks a causal relationship in another mental space than the conceptualizer's. The relations between the conceptual structure of Figure 5 and linguistic material in (1) are as indicated by means of italicization in Figure 6:

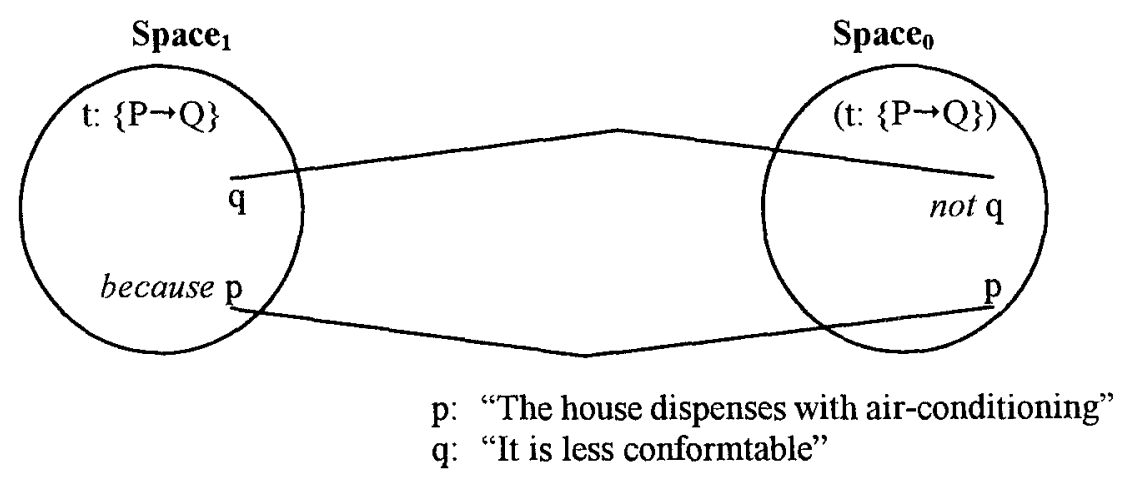

Figure 6. Mental Space representation of (1)

In the concessive interpretation, the causal conjunction must mark a relation in another mental space than the conceptualizer's; the latter is the one containing the denial of $\mathrm{q}$, and the associated linguistic element not. This explains why it is the so-called wide-scope interpretation of negation that corresponds to the concessivity: in this interpretation, the 
because-relation cannot hold in the same space as the negation, thus it is itself negated. Note, furthermore, that Figure 6 actually gives a more accurate picture of the interpretation than a one-dimensional formula for wide scope negation of the type "not ( $q$ because $p$ )", as the latter does not explicitly indicate that "not $\mathrm{q}$ " is actually asserted in the conceptualizer's space.

Note that the interpretation of the element because does not have to be assigned to another mental space when it occurs in the context of negation. But when it is interpreted as belonging to the same mental space as not, then the same conceptualizer takes responsibility for the negation and for the causal inference, and a so-called narrow scope interpretation is the result.

By itself the causal connective because does not indicate the relevance of multiple viewpoints, but in a context of two mental spaces it may apparently be used to mark causality in either one of these, as long as the overall interpretation of the utterance is not selfcontradictory. Another example of a causal connective demonstrating this possibility is the following, from a Dutch newspaper text:

De nieuve tariefstructuur is marktconform, maar daarom niet per definitie klanturiendelijk.

'The new price structure is in accordance with market rules, but therefore not by definition customer-friendly.'

The causal connective daarom ('therefore') evokes an inference from being in accordance with market rules to being customer-friendly, and since the latter is denied by the conceptualizer while the former is acknowledged, the causal inference must be assigned to another mental space than the conceptualizer's.

The conceptual structure represented in Figure 5 may also be marked in other ways. As we have argued, a concessive connective like although is itself an indication for projecting a mental space containing a causal inference that is invalidated in the conceptualizer's space. That is, the conceptual structure that is evoked by marking causality in a projected space-as in (1) and (9)-may also be evoked by a single element that conventionally indicates this structure, i.e. a concessive connective. As Figure 7 shows, the mental space configuration evoked by although in (2) shares its structure with the constellation in Figure 6: the same conceptual relationships (depicted in a general way in Figure 5 ) are realized in linguistically different ways. 


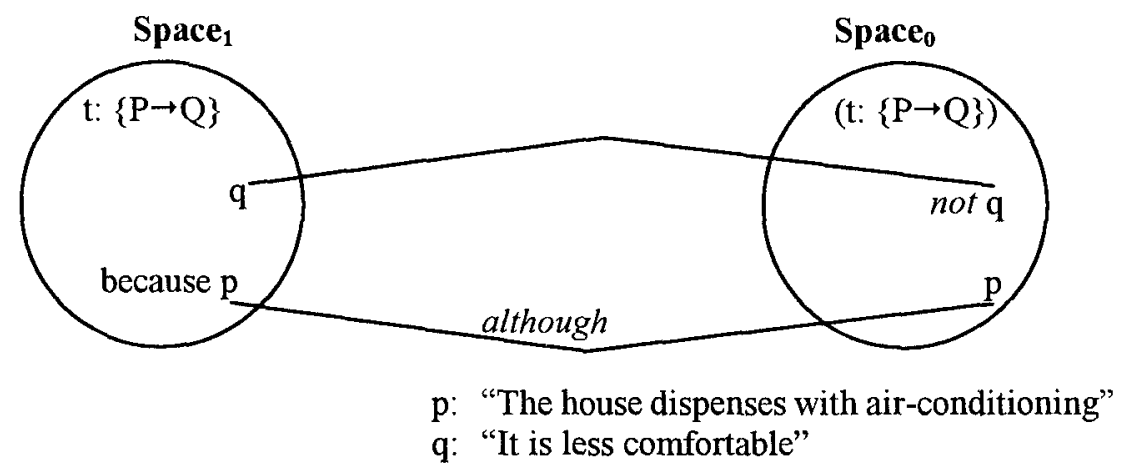

Figure 7. Mental Space representation of (2)

Thus, the connections between causality and concessivity that we started this discussion with appear to fall out from the mechanisms of Mental Space theory automatically.

What is more, it also follows from this approach that the relationship is not one of complete duality, for a reason that may now appear very simple. What would it amount to, in this view, to try to negate a concessive relation? This would have to involve the projection of a mental space containing both mental spaces involved in the concessive relation, and their connections-not simply another mental space projected from the space functioning as the background to the conceptualizer's one. In section 5.1, we claimed that the qualitative difference between causal and concessive relations is that the former do not necessarily lead to the construction of multiple spaces while the latter do. And there is no way to get a single mental space constellation as in Figure 1 from the multiplication of mental spaces. On the contrary, that way one can only get more and more complicated constellations; recall that a sentence such as (10) is virtually uninterpretable:

\section{"It is not the case that John failed his exams although he worked hard.}

Interestingly, examples that have the same grammatical structure as (10) and that appear to fit the above characterization (a mental space that contains both other spaces and their interconnections) are not at all hard to find: 
(11) Beatie finds that although she has lost a lover she has gained her freedom.

In fact, even a negation in the matrix clause of such constructions seems to be possible in principle:

(12) They could not believe that although John had worked hard, he failed his exams.

What seems to make this example so much better than (10) is the factivity of the matrix predicate in (12); when I say $X$ could not believe that $p, \mathrm{I}$ am still committed to the truth of $\mathrm{p}$ myself, unlike when I say It is not the case that $p$. Thus, in both (11), a non-negative sentence, and (12), negative but factive, the embedded propositions are not contradicted in the primary conceptualizer's mental space: in Space, there simply is no denial of "p although q". The problem with (10) on this view is that it contains two instructions (not the case and although) to set up mental spaces as alternatives to the conceptualizer's, and that these cannot be properly related to each other.

It is interesting to note that with a non-factive matrix predicate the interpretation of the entire sentence becomes unclear:

\section{(13) 'They did not conclude/think that although John had worked hard, he failed his exams.}

When I say $X$ did not think that $p$, my utterance may well be taken as an indication that $I$ am at least uncertain about $p$ myself, unlike the situation with factive predicates. Consequently, if the complement clause contains a concessive one, this would be in the scope of the 'uncertainty operator' and the same problem of distinct spaces with a non-positive epistemic stance would arise as in (10). Whatever the details of the analysis of these cases, they help to show clearly that the problem with the interpretation of a negation having a concessive clause in its scope is a problem of manipulating points of view: when there are several of them, it may be hard or even impossible to relate them to each other in a consistent manner. 


\section{Conclusion}

In retrospect, the crucial problem in previous approaches to the connection between causality and concessivity seems to lie in the implicit single-viewpoint conception of negation, as no more than the reversal of truth value. This creates the illusion that two negations cancel each other out, whereas in natural language and cognition negation (also as a part of concessivity) involves the construction and manipulation of different viewpoints (cf., again, Ducrot 1996, and earlier work), or in terms of the present framework: mental spaces. This framework, motivated independently of the issue that concerned us here, turns out to offer a prospect for a truly explanatory account. Since only a very limited range of phenomena has been taken into account in this paper, an important task is, of course, to test the approach against a larger body of data. Yet I believe that it has proven worthwhile to spend some space and energy on a mainly conceptual issue: what we understand precisely when we call a phenomenon a case of 'concession' or 'negated causality' crucially involves the manipulation of multiple distinct though interconnected viewpoints; therefore it differs qualitatively and irreversibly from the conceptualization of causality per se, which need not demand the construction of more than one mental space.

\section{Notes}

1. There is quite a variety of labels for this concept, such as topos, (discourse) presupposition, conventional implicature, defeasible implication. For some analysts these are probably not the same, but the differences do not have to concern us here. The term for this kind of "inference licensing rules" that I will use myself later in this paper is "topos". It stems from Anscombre \& Ducrot's theory of argumentation in natural language, e.g. $(1983,1989)$. See also Ducrot $(1984,1996)$.

2. Thus I am in full agreement here with König and Siemund's emendation of Pasch's analysis (cf. their section 4). What they fail to note, however, is that it is not only a matter of descriptive adequacy that the 'background assumption' involves some kind of generalization, but actually one of conceptual necessity. As observed with respect to (8), this schema (as well as the right hand column of Table 2 in König and Siemund (this volume)) leads to a straightforward contradiction, as it entails both $q$ and $\neg q$. In order to avoid this, only the propositions $\mathrm{p}$ and $\mathrm{q}$ themselves should be allowed to represent particulars ("singular statements" in terms of Popper (1972)), thus allowing for verification (cf. Popper 1972: 27, 33, and elsewhere); the background 
assumption must be some general rule whose logical form does not allow for verification. For similar reasons, the background assumption must be 'only' general and not universal; if it were truly universal, e.g. with $q$ in the presupposition taken as " $\forall x(f(x))$ ", the use of a concessive, asserting $p \& q$, would again entail a contradiction ( $p$ and $\neg p$ ). These points have been elaborated in other contexts before (cf., for example, Lagerwerf (1998) and some references cited there), and especially in work in the tradition of Anscombre and Ducrot's theory of argumentation in language. As Ducrot (1996: 144) suggests, it might in fact be much older: "When we say ['It's warm, let's go for a walk'], we do admit that there might be exceptions but that does not prevent the topos from being valid, which is the point this highly famous formula attributed to Aristotle makes: 'exceptions make it possible to uphold the rule in unforeseen cases'.".

3. Precise terminology may be important here. Notice that what is to be avoided is the attribution of contradictory beliefs. It is, of course, no problem to entertain contradictory propositions. In fact, Mental Spaces is an explication of what is involved in doing just that.

4. It should perhaps be pointed out that this description is not a full semantic analysis of a linguistic element such as although (though it does provide essential conceptual structure that will have to enter into such an analysis). For example, this description does not yet provide a basis for distinguishing between although and but, whereas the functions of these words are not identical.

5. Abductive reasoning is a sufficient but not a necessary condition for the construction of multiple spaces: a deductive inference as in may also be construed as an argument to take away doubt. In domain terms, and informally: content causality may always be 'used as' epistemic causality, but the reverse does not hold.

6. This is a point, by the way, where I disagree with a specific polyphonic analysis. It is sometimes proposed that such a distribution of old-newinformation should be analyzed in terms of two voices, one asking the question ("Why?" or "How?"), the other providing the answer. In my view, such a move threatens to destroy the usefulness of the concept, since it would actually make it quite hard again to represent the difference between content and epistemic causality.

7. In these and the following mental space representations of concessives, I will leave out the connectors between the topos-representations (one obligatory and one optional) in the different spaces, in order to make the pictures somewhat simpler to read.

\section{References}

Anscombre, Jean-Claude, Oswald Ducrot

1983 L'argumentation dans la langue. Bruxelles: Mardaga.

1989 Argumentativity and informativity. In: Michel Meyer (ed.), From Metaphysics to Rhetoric, 71-87. Dordrecht, etc.: Kluwer Academic Publishers. 
Ducrot, Oswald

1984 Le dire et le dit. Paris: Editions Minuit.

1996 Slovenian Lectures/Conférences Slovènes. Argumentative Semantics/ Sémantique argumentative. Editor/Éditeur Igor Ž. Žagar. Ljubljana:

Fauconnier, Gilles ISH Inštitut za humanistične študije Ljubljana.

1994 Mental Spaces. Aspects of Meaning Construction in Natural Language. Cambridge: Cambridge University Press.

1998 Mental spaces, language modalities, and conceptual integration. In: Michael Tomasello (ed.), The New Psychology of Language. Cognitive and Functional Approaches to Language Structure, 251279. London/Mahwah, NJ: Lawrence Erlbaum Ass..

Fauconnier, Gilles, and Eve Sweetser (eds.)

1996 Spaces, Worlds, and Grammar. Chicago/London: The University of König, Ekkehard Chicago Press.

1991 Concessive relations as the dual of causal relations. In: Dietmar Zaefferer (ed.), Semantic Universals and Universal Semantics, 190209. Dordrecht: Foris.

1994 Concessive clauses. In: R.E. Asher (ed.), The Encyclopedia of Language and Linguistics, 679-681. Oxford: Pergamon Press.

Lagerwerf, Luuk

1998 Causal Connectives have Presuppositions. Effects on Discourse Structure and Coherence. Den Haag: Holland Academic Graphics.

Pasch, Renate

1992a Sind kausale und konzessive Konstruktionen Duale voneinander? [=Arbeiten des Sonderforschungsbereich 282-Theorie des Lexikons, Nr. 31]. Düsseldorf: Heinrich-Heine-Universität.

1992b Kausale, konzessive und adversative Konnektive: Konnektive als Mittel des Ausdrucks von Diskurspräsuppositionen. Münstersches Logbuch zur Linguistik 1, 33-48.

1994 Konzessivität von wenn-Konstruktionen. Tübingen: Narr.

Popper, Karl R.

1972 The Logic of Scientific Discovery. London; Hutchinson \& Co. [First Sweetser, Eve E. English edition 1959]

1990 From Etymology to Pragmatics. Metaphorical and Cultural Aspects of Semantic Structure. Cambridge: Cambridge University Press. 